УДК 82І.ІІІ.о

ББК $83.3(4$ Вел $) 52$
ФУНКЦИЯ ОБРАЗНОГО ЯЗЫКА

В РОМАННОМ ДИАЛОГЕ Ч. ДИККЕНСА

С ЧИТАТЕЛЕМ

(C) 2020 г. Е.А. Шевченко

Российский государственный гуманитарный университет, Москва, Россия

Дата поступления статьи: о6 апреля 2020 г.

Дата публикащии: 25 декабря 2020 г.

DOI: https://doi.org/IO.22455/2500-4247-2020-5-4-I66-I8I

Аннотация: В статье рассматриваются закономерности функционирования образного языка Ч. Диккенса в свете уточненного представления о природе его диалогизма. Диалогизм Диккенса, отмеченный М.М. Бахтиным и проявляющийся в двухголосии и социально-идеологическом разноречии, находит продолжение в диалоге как отношениях между автором и читателем, возникающих посредством текста. Второй вариант диалога вбирает в себя первый. Влияние потребности в интенсивном контакте с читателем на все стороны творчества Диккенса, в том числе сам дискурс, ранее рассматривалось. В настоящем исследовании предпринимается попытка совместить два подхода, проследив взаимосвязь и процесс перехода между диалогом, возникающим вокруг материала в ходе взаимоориентации голосов, и диалогом автора-читателя, направлявшим все творчество Диккенса в сторону экстенсивной диалогичности. Как показывает анализ, образные выражения выполняют две функции: одновременно служат усилению многоголосия романов и обнаруживают авторскую интенцию, создавая общее пространство коммуникации автора и аудитории, призывая читателя в эмоциональные соучастники процесса. Образность, интонационноэмоциональная выразительность речи Диккенса способствует углублению и умножению форм диалога.

Ключевые слова: Диккенс, диалог, диалогизм, образность, сравнения, метафора, Бахтин, читатель, игра слов, ирония, шутка, автор, язык, дискурс, заимствование.

Информация об авторе: Елизавета Александровна Шевченко - аспирант, преподаватель, Российский государственный гуманитарный университет (РГГУ), Миусская пл., д. 6, І25993 г. Москва, Россия.

ORCID ID: https://orcid.org/oooo-0002-5798-3605

E-mail: elizshevchenko@yandex.ru

Для цитирования: Шевченко Е.А. Функция образного языка в романном диалоге Ч. Диккенса с читателем // Studia Litterarum. 2020. Т. 5, № 4. С. I66-І8I. https://doi.org/I0.22455/2500-4247-2020-5-4-I66-I8I 


\title{
THE FUNCTION OF FIGURATIVE LANGUAGE IN THE DIALOGUE BETWEEN DICKENS AND HIS READER
}

This is an open access article distributed under the Creative Commons Attribution 4.0 International (CC BY 4.0)

\author{
(C) 2020. E.A. Shevchenko \\ Russian State University for the Humanities (RSUH), \\ Moscow, Russia \\ Received: April 06, 2020 \\ Date of publication: December 25, 2020
}

\begin{abstract}
The article examines the function of figurative language in Dickens's novels in the light of its specific dialogism. Dickens's dialogism mentioned by M. Bakhtin manifests itself through the so-called double voicing and socio-ideological heteroglossia. It also continues in the form of a dialogue between the author and the reader. The second type of the dialogue includes the first one. The essay explores the hitherto understudied influence of Dickens's communicative urge for the continuous contact with his reader in his fiction, including its discursive aspects. My research is an attempt to converge these two approaches as I trace the interdependence and the process of transition between the dialogue that develops in the frame of the voice orientation and the dialogue between the author and reader that leads Dickens to extensive dialogism. The analysis shows that the figurative discourse implements two functions: it intensifies heteroglossia and at the same time clarifies the author's intention and also organizes the space of the author's and reader's communication, appealing to the reader to emotionally engage in the process. Figurative and emotional force of Dickens's language is a means to strengthen the dialogical discourse and to multiply its forms.
\end{abstract}

Keywords: Dickens, dialogue, dialogism, figurative, imagery, comparison, metaphor, Bakhtin, reader, wordplay, irony, joke, author, language, discourse, borrowing.

Information about the author: Elizaveta A. Shevchenko, PhD Student, Lecturer, Russian State University for the Humanities, Miusskaya sq. 6, I25993 Moscow, Russia.

ORCID ID: https://orcid.org/oooo-0002-5798-3605

E-mail: elizshevchenko@yandex.ru

For citation: Shevchenko E.A. The Function of Figurative Language in the Dialogue between Dickens and His Reader. Studia Litterarum, 2020, vol. 5, no 4, pp. I66-I8I. (In Russ.) https://doi.org/Io.22455/2500-4247-2020-5-4-I66-I8I 
Представление о специфическом диалогическом дискурсе диккенсовского нарратива находит основание в двух методологиях. Первая - концепция диалогизма М.М. Бахтина. В работе «Слово в романе», где получает оформление теория монолога и диалога как двух жанрообразующих типов речи, согласно которым выстраиваются две линии развития европейского романа, именно творчеством Диккенса Бахтин подробно иллюстрирует диалогический тип, давая пример разбора социально-идеологического разноречия фрагмента из «Крошки Доррит». Считая Диккенса образцом диалогической романной формы, Бахтин отмечает не только разнообразие языков, но и тонкость переходов между ними: «Весь его текст, в сущности, можно было бы испещрить кавычками, выделяя островки рассеянной прямой и чистой авторской речи, со всех сторон омываемые волнами разноречия. Но сделать это было бы невозможно, так как одно и то же слово, как мы видели, часто входит одновременно и в чужую и в авторскую речь» [I, с. I2I]. Вариации бахтинских двухголосия и гибридизации, распространенные в викторианском романе, проследил впоследствии У. Хэррис [І4].

Второе обоснование интенсивной диалогичности, в сущности, близкое Бахтину в идее о взаимопроницаемости социального и эстетического, но в большей мере ориентирующееся на синхронический анализ литературы и культурных практик, заключается в специфике всего жизненного уклада XIX в., при котором не просто стремительно происходит трансформация типов коммуникации, но и, как никогда прежде, в целом возрастает роль ее самой. Так, Т. Венедиктова отмечает, что практика обмена в процессе коммуникации определяет мировоззрение этой эпохи: «Отношения обмена всегда присутствовали в социальной жизни человека, “современность” 
лишь сделала их всеобъемлющими» [2, с. 38], - пишет она. Викторианцы понимают жизнь как взаимодействие, диалог, осуществляющийся между всеми, в том числе несходными и противоположными явлениями, которые влияют друг на друга, - между материальным и духовным, видимым и невидимым, прошлым и настоящим. По утверждению Р. Менке, «для викторианцев - исследователей, мыслителей, равно как и для романистов, сеть (network) становится схемой, которая организует подлинный взаимообмен, невидимой или плохо видимой системой связей и разрывов, которая лежит в основании повседневности» [16, p. I5]. Включаясь в «сеть», литература транслирует парадигму всеобщего обмена на всех уровнях, начиная с проблематики и моделей дискурса и заканчивая профессионализацией и коммерциализацией своей сферы.

Однако если культурно-исторический подход позволяет объяснить выбор Бахтиным именно Диккенса (а не более ранних авторов) в качестве образца романа диалогической линии, он одновременно и лишает писателя исключительности на фоне его современников. Между тем, по замечанию М. Урнова, стиль Диккенса для его эпохи был новаторским, поскольку он «первый так отчетливо и специфично разделил жизненный материал и впечатление, создаваемое писателем на этом материале» [4, с. 478]. Ставя своей задачей производство впечатления, стиль Диккенса приобретает подвижность, свободу и независимость от материала и делает автора и читателя причастными новому, художественному миру, объясняет Урнов [4]. В установке на впечатление, следовательно, реализуется еще один диалог - человеческий, живой, практически осязаемый контакт с читателем, потребность в котором оказывала воздействие на внутреннюю форму текстов. Таким образом, бахтинское социально-идеологическое разноречие включается в диалогические отношения, возникающие между автором и читателем. На многозначность понятия диалога и возможность диалогов разных уровней в литературе обратил ранее внимание Хэррис [І4], однако не развил эту мысль в ходе анализа. В нашей статье на примере образных выражений, т. е. фрагментов, наиболее ярко демонстрирующих свободу диккенсовского стиля, мы попробуем совместить сделанное упомянутыми исследователями, проследив взаимосвязь и процесс перехода между диалогом, возникающим вокруг материала в ходе взаимоориентации голосов, и диалогом автора-читателя, направлявшим все творчество Диккенса в сторону экстенсивной диалогичности. 
Ориентация на читателя - знак эпохи. Так, в трактате Джорджа Генри Льюиса «Принципы успеха в литературе» (впервые опубликован в I865 г.) рассуждение начинается именно с читателя: успех у читателя, пишет Льюис, является абсолютным показателем достоинств произведения, между успехом (его бурным выражением и продолжительностью) и достоинствами существует прямая зависимость. «Это не удача, а конкретное соответствие между сознанием автора и потребностями публики. <...> Мы можем положить за правило, что никакая работа не имеет успеха, даже на один день, если только она не заслуживает этот успех» [I5, p. 26]. Сам трактат направлен на исследование «причин, которые определяют успех в точном соотношении с природной силой, с одной стороны, и состоянием общественного мнения, с другой» [15, p. 34]. Писатель и читатели выступают полюсами непрерывной коммуникации, которая осуществляется посредством литературы. Текст в сущности не просто выполняет коммуникативную роль, а получает в ней свое смысловое завершение, становится текстом постольку, поскольку существует между сознанием писателя и сознанием читателей, или, иначе, существует на границе между ними.

Читатель в середине века мыслится адресатом, в ценностном поле которого автор работает, и исходя из этого ценностного поля он строит текст, будь это текст лирический или прозаический. Например, принципы поэтического творчества, которым нужно сегодня следовать, Мэтью Арнольд в предисловии к сборнику стихов I853 г. обосновывает исходя из читателя: «Нужно, чтобы оно (изображение. - Е.Ш.) не только интересовало, но и вдохновляло и радовало читателя: так что оно должно передавать очарование и вызывать восторг» [5, p. vii]. Как пишет Н. Дэймс, критика литературы в середине века состояла в объяснении «сил формы», в смысле способности ее влияния: викторианцы судят о литературе по производимому ею впечатлению на читателя. Поэтому, продолжает он, рассуждения в профессиональной среде писателей-романистов идут о том, «каково эмоциональное и познавательное воздействие романного нарратива на читателя, а не о каких-либо вопросах романной конструкции», которая сама по себе еще не ощущается как ценность [8, p. 508].

Ориентация на читателя для викторианца предполагает двунаправленный процесс: учитывание читательских потребностей (при этом литература стоит в позиции подчинения, позиции отвечающего) и формирование 
читательских представлений (с позиции наставника). Такие отношения по форме представляют диалог, и Диккенс остро ощущает себя его участником. Все стороны произведения, включая манеру изложения, предметы изображения и сюжетные линии, он оценивает исходя из их предполагаемого воздействия на читающего, из мыслей и чувств, которые станут откликом на прочитанное. При этом Диккенс не просто стремится вызвать чувства - его подход к читателю можно назвать очень личным, дружеским. Он вникает в характер возможных читательских переживаний и, если они видятся ему тяжелыми, не выпускает произведение в свет. «Я сообщил Уилсу, что не знаю, счел ли бы я себя вправе предложить вниманию столь многочисленных читателей страшную проблему наследственного безумия, когда, весьма возможно, многие - в лучшем случае некоторые - из них с ужасом угадают в этом свое личное несчастье» [3, т. 30, с. I4], - пишет он Парр. В другом случае он отказывает в публикации произведению, в котором сам с художественной точки зрения признает отсутствие изъянов: «Вся повесть настолько продуманна, что любые подробности кажутся необходимыми и соответствующими целому. Я по совести не могу предложить автору сделать какие-либо значительные сокращения. На мой взгляд, это было бы решительным образом неправильно - во всей рукописи я не заметил, пожалуй, ни одной детали, которая не была бы существенной частью всей грустной картины. Остаются, однако, две трудности, делающие ее неприемлемой для “Домашнего чтения”. Во-первых - ее длина. А во-вторых - главная ее идея. Эта ужасная возможность - а скорее, даже вероятность - угрожает стольким людям без какой бы то ни было вины с их стороны, что боюсь, как бы эта повесть не причинила много горя, если мы предложим ее нашим многочисленным читателям. Я страшусь взять на себя ответственность и пробудить ужас и отчаяние, дремлющие, быть может, в стольких сердцах. Поэтому я с большой неохотой пришел к заключению, что нам не остается иного выхода, как вернуть повесть автору» [3, т. 30, с. І6]. Само по себе произведение не имеет для Диккенса ценности, цели и смысла - смысл его в моменте контакта, в действии, которое оно производит на публику. Акт литературного творчества - это акт влияния большой силы. Поэтому для Диккенса исключительно важным требованием к литератору становится требование осознания личной ответственности за свои действия. Цензура, которую Диккенс налагал на изображение безнравственных явлений (как 
по отношению к своим текстам, так и к авторам, печатавшимся в его журналах), вытекала из личного кодекса морали, проистекающего из осознания ответственности литературного письма как работы по формированию коллективных представлений.

Мысль о поддержании и интенсификации контакта с читателем руководила всей художественной деятельностью Диккенса. В процессе активной переписки с аудиторией, внимая ее пожеланиям, он подвергал порой серьезным изменениям даже сюжетные линии и образы персонажей ${ }^{\text {. По- }}$ мимо основанных им журналов, где он мог выступать в предполагающих прямой контакт с адресатом публицистических жанрах, формой диалога с аудиторией были организуемые им любительские спектакли, а также необыкновенно увлекавшие его публичные чтения и встречи с читателями. Изобретенный им формат романов ежемесячными выпусками - по образцу периодической печати ${ }^{2}$ - также во многом был воплощением его потребности в постоянном ощущении присутствия его аудитории. Именно потому, что здесь был личный элемент, считает С. Элиот, после многочисленных попыток повторить «сериальный успех» Диккенса все писатели, начиная от малоизвестных и заканчивая Теккереем и Троллопом, в конце концов покинули поле, «оставив Диккенса хозяином», каковым он был до своей смерти, вместе с ним ушла со сцены и изобретенная им романная форма [II, p. 44].

Найденный Диккенсом формат помогал реализовать ему то, что он и считал основной задачей литературы. Роман в виде многомесячной журнальной серии (а не в нескольких томах - форма, ко времени Диккенса в Англии сложившаяся и ставшая привычной) «выражал эффективность диккенсовской максимы о том, что “повествователь и читатель должны установить взаимопонимание так быстро, как только возможно” и его собственное мастерство в этом», - отмечает К. Флинт [ı2, р. І8]³. И Венедиктова указывает, что это «создавало у сторон литературного взаимодействия ощущение необыкновенно тесного, плотного контакта, а также взаимопроникновение социального опыта и опыта книжного» [2, с. 6о].

\footnotetext{
I Связь творческого процесса с заботой о мнении аудитории отражена в биографии Д. Форстера [13], также много подобных примеров содержит биография, написанная М. Слэйтером [І7].

2 Большинство романов впервые публиковались в виде специальной серии ежемесячных выпусков, только некоторые были впервые напечатаны в журналах, выходивших еженедельно. 3 Флинт цитирует «Колокола» - рождественскую повесть Диккенса.
} 
Сериальный формат (и его экономическая доступность) не только создавал более активное поле взаимодействия, но и создавал роман нового типа - роман, чья культурно-социальная форма служила закономерным продолжением его поэтики, нарративной структуры, самого дискурса. Диккенс добивался того, чтобы в его творчестве все аспекты подчинялись его представлениям о романе и романном слове как диалогической, социально-дискурсивной практике.

Приемом интенсификации диалога с аудиторией становятся и элементы образной выразительности. Художественная речь Диккенса характеризуется яркой образностью, обилием сравнений, метафор, сопоставлений, игры слов. И хотя в образных выражениях можно выделить социальные языки, точки зрения, заимствования типов дискурса, само «обыгрывание» этих языков, их смена и смешение служат их объективации и появлению еще одной точки зрения. Так за повествованием обнаруживает себя фигура автора - того, кто является создателем сравнений и метафор, кто обнаруживает в языке потенциал для шутки, кому приходят в воображении образы.

Например, все «громче» звучит авторский голос, все ярче выдвигается он на первый план в сцене разговора между Флоренс Домби и Тутсом. Этот голос поначалу выступает в функции аккомпаниатора:

After stating this curious and unexpected fact, $\mathrm{Mr}$ Toots fell into a deep well of silence.

'You have left Doctor Blimber's, I think?' said Florence, trying to help him out.

'I should hope so,' returned Mr Toots. And tumbled in again.

He remained at the bottom, apparently drowned, for at least ten minutes. At the expiration of that period, he suddenly floated, and said,

'Well! Good morning, Miss Dombey.'

$<\ldots>$

You remember his remembering Diogenes?'

'Oh yes! oh yes!' cried Florence.

'Poor Dombey! So do I,' said Mr Toots. 
Mr Toots, seeing Florence in tears, had great difficulty in getting beyond this point, and had nearly tumbled into the well again. But a chuckle saved him on the brink [9, p. I78-I79] $]^{4}$.

Метафора “deep well of silence”, возникнув однажды в воображении повествователя, будто перестает быть иносказательным образом и становится для говорящего императивом, подталкивая его к тому, чтобы интерпретировать все дальнейшее поведение Тутса как человека, проваливающегося в физическом смысле. Описание попадает в плен образа метафоры и развивается в ее поле в поиске новых собственных возможностей, при этом по мере развертывания сцены речь повествователя приобретает всё большую самостоятельность по отношению к описываемому - такую, что образ края колодца под конец ощущается как обязательный для проговаривания, словно вопрос бы был именно в колодце и его отношении к героям. Подобное нарушение «стилистической иерархии предметов» Урнов назвал основным принципом диккенсовского стиля [4, с. 488].

Сам Тутс уходит на второй план, а его состояние постепенно проясняется более через найденное повествователем сопоставление, чем через его собственную речь. Это речевое преобразование согласуется с характером самого Тутса - неловкого как в поступках, так и в речи юноши, туго понимающего и слова, и мысли, и смысл действий окружающих. Такой герой словно закономерно попадает в сети чужого (для него, Тутса, авторский язык - чужой) языка, оказывается опутан одной случайно родив-

4 Сообщив об этом любопытном и неожиданном факте, мистер Тутс провалился в глубокий кладезь молчания.

- Кажется, вы расстались с доктором Блимбером? - сказала Флоренс, помогая ему выкарабкаться.

- Надеюсь, - ответил мистер Тутс. И снова полетел вниз.

Он пребывал на дне, по-видимому захлебнувшись, по крайней мере десять минут. По истечении этого срока он вдруг всплыл на поверхность и сказал:

- Ну, всего хорошего, мисс Домби.

$<\ldots>$

Вы помните, как он вспоминал о Диогене?

- О да! Да! - воскликнула Флоренс.

- Бедняга Домби! Я тоже помню, - сказал мистер Тутс.

При виде плачущей Флоренс мистеру Тутсу великого труда стоило перейти к следующему пункту, и он чуть было не свалился опять в колодезь. Но хихиканье помогло ему удержаться у самого края [3, т. I3, с. I24]. 
шейся шуткой. Начавшись как интерпретация-пояснение, образ колодца преобразовывается в доминанту, смысловой акцент переносится на метафорический комментарий ситуации. При этом шутливое образное пояснение следует атрибутировать как авторское слово. С нарастанием смеховой ноты присутствие автора становится все ощутимее, его прямое обращение к читателю - все яснее. Задача образного комментария к диалогу - культивирование связи с читателем, единение читателя и автора в позиции наблюдателя-союзника. Образно-речевая игра организует между ними общее эмоциональное пространство, при этом их общность подчеркивается исключением из нее остраняемого героя - Тутса, который противопоставляется единству автора с читателем как незнающий - понимающим.

Ведя словесно-образную игру, диккенсовский повествователь включает в нее читателя, призывая его в эмоциональные соучастники процесса. Способом создания игрового пространства речи, в котором автор и читатель будут переживать сходные чувства, становится переосмысление устойчивых выражений: "It is said that every life has its roses and thorns; there seemed, however, to have been a misadventure or mistake in Stephen's case, whereby somebody else had become possessed of his roses, and he had become possessed of the same somebody else's thorns in addition to his own" [1о, p. 75]5. Снятая с языка молвы и имеющая религиозно-христианские коннотации метафора жизненного пути человека как чередования роз и терний переосмысляется в буквально-механистическом контексте - контексте, актуальном для прагматичного мышления кокстаунских промышленников, в том числе Баундерби, в чьей власти и находится рабочий его фабрики Стивен. Диккенс в данном случае создает ситуацию взаимного освещения языков и мышлений. Первая часть фразы выстроена в логике религиозно-аллегорической, абстрактной, вторая - в логике буквально-светской, практическо-математической. Однако и та, и другая оказываются равно удалены от единичной судьбы несчастного Стивена, который словно остается между языками неприкаянным, не попадающим ни в один фокус. Эмоциональная сила фразы складывается из иронии от этого несовпадения (иронии, кото-

5 Говорят, у каждого в жизни свои розы и тернии. Но казалось, однако, что в случае со Стивеном произошло какое-то несчастье или ошибка, в результате которой его розы достались кому-то другому, а ему взамен и в придачу к его собственным перешли чужие тернии. Пер. мой. - Е.Ш. 
рая распространяется и на религиозно-абстрактную мысль, и на буквалистский подход, и на самого Стивена), смешанной с жалостью и сочувствием к герою. Интенция обращения к читателю задана с первого слова - с обсуждения с читателем того, что «говорят». Далее же повествователь перебирает точки зрения, имитируя поверх присущей им иносказательности свою собственную иносказательность, рассчитывая, что читатель следит за ходом речи и уловит непроговоренное.

Религиозное слово, по своей жанровой природе абстрактно-образное, подсказывает Диккенсу продуктивную модель для новых образных выражений, удовольствие от которых должны разделить автор и читатель. «Отталкивание» происходит от общей точки, общего, известного авторитета. Так роман «ассимилирует» метафору «заблудшие овцы» из языка религиозной проповеди: "The two stray sheep in question were penned by a beadle in a commodious pew <...> [9, p. 563 $]^{6}$, описываются прихожане в церкви в «Домби и сыне». Перенос слова, тесно связанного с религиозным жанром, в роман создает пространство диалога автора и читателя по поводу этого слова, становящегося объектным, обсуждаемым. Его авторитет, защищенный жанром, универсальность, принципиальная самостоятельность разрушаются оторванностью от реальных обстоятельств жизни, когда метафора применяется к единичной ситуации. Автор будто притворяется перед своим адресатом, что заимствует чужой дискурс по необходимости, однако функцию этой игры с языком можно определить как адресную шутку в сторону читателя.

Сложность логических словесных ходов, свободная игра с языком и образами, требующая для своего понимания чуткого ощущения связей между предметом и условностью, говорят о большом авторском доверии и вере в своего читателя. Сталкиваясь с образным выражением и необходимостью его «расшифровать», он оказывается прежде всего перед задачей определить его истоки: насколько высказывание вызвано предметом повествования, насколько - характером автора, желающего себя обнаружить, дать волю своей фантазии. Второй мотив порой выступает вперед: “She was dry and sandy with working in the graves of deceased languages. None of your live languages for Miss Blimber. They must be dead - stone dead - and then

6 Две заблудившиеся овцы были загнаны бидлом на удобную скамью <...> [3, т. I3, c. 427]. 
Miss Blimber dug them up like a Ghoule" [9, p. IоI] 7. Стертая метафора «мертвый язык» вызывает пассаж, игровой и устрашающий одновременно. При этом к мисс Блимбер повествователь не испытывает негативных чувств, и ни до, ни после цитаты они не проявятся. Но внешность девушки, с одной стороны, и метафора, замеченная к случаю, с другой, не позволяют от игры отказаться. Так, возникая далее снова в течение романа, шутка про мисс Блимбер служит прямым обращением к читателю, будто проверкой - рядом ли он, помнит ли шутку, понимает ли.

Стремясь к диалогу с читателем, Диккенс использует имманентное свойство метафоры, которое в романе преобразуется в функцию: это свойство - культивация интимности. Оно было отмечено Т. Коэном; метафора, пишет он, это уникальный путь, на котором говорящий и слушающий становятся ближе: говорящий как бы задумывает и посылает особое приглашение, слушающий совершает две операции: сначала догадывается, что перед ним метафора, а затем добирается до ее значения, в результате между ними создается признанная общность (acknowledgment of a community). При этом слушающий перебирает «множество предположений по поводу говорящего: чему говорящий верит, что полагает говорящий по поводу того, что думает слушающий (что включает и мысли о том, что, как говорящий думает, слушающий может ожидать от представлений о нем слушающего)» $[6, \text { p. 8] }]^{8}$. В самом деле, обнаруживая не только мастерство владения словом и силу воображения, но и склонность к определенным образам, шуткам и логическим ходам, метафора несет на себе ясно ощущаемый отпечаток личности говорящего, его характер и минутное настроение, и, таким образом, становится знаком доверия, особой искренности, сближая роман с лирическими жанрами ${ }^{9}$. Метафорическое слово создает между автором и читателем отношения интимности, близости, предполагая ответную включенность читателя, строя его образ на основании предположения о его личностном потенциале к восприятию. Метафора заключает в себе предчувствие ответного понимания, реакции, делая участников такого общения, по словам

\footnotetext{
7 Она усохла и покрылась песком, раскапывая могилы мертвых языков. Живые языки не нужны мисс Блимбер. Они должны быть мертвыми - безнадежно мертвыми, - а тогда мисс Блимбер выроет их из могилы, как вампир [3, т. г3, с. г8о].

8 Теорию интимности метафоры после Коэна развил Д. Купер [7].

9 Теорию о разделении лирических и прозаических жанров по ориентации их дискурса на метафорические и метонимические сформулировал Р. Якобсон.
} 
Коэна, «парой близких» (intimate pair) [6, p. 9]. На фоне всего художественного языка она выделяется тем, что «выраженно инициирует взаимный акт понимания». Анализ образного языка Диккенса, в котором отмечается преобладание метафор и метафорических сопоставлений, может служить подтверждением мысли Коэна.

Образность, интонационно-эмоциональная выразительность Диккенса неразрывно связана с его потребностью в контакте и диалоге со своей аудиторией. В самом деле, на взаимообусловленность двух факторов обращал внимание еще В. Волошинов: «Творчески продуктивная, уверенная и богатая интонация возможна только на основе предполагаемой “хоровой поддержки”. Там же, где ее нет, голос срывается, его интонативное богатство редуцируется, как это бывает со смеющимся, когда он вдруг замечает, что смеется один: смех смолкает или вырождается, становится надрывным, теряет свою уверенность и ясность и уже не способен породить шутливых и веселых слов» ${ }^{\mathrm{I}}$. Без острого ощущения присутствия читателя, без непрерывной мысли о нем стиль Диккенса был бы другим - без искрящегося, образно-метафорического, вечно пробивающегося в толщи языка стиля у его романов была бы иная читательская судьба.

\section{Список литературы}

I Бахтин М.М. Слово в романе // Вопросы литературы и эстетики. М.: Худож. лит., $1975.502 \mathrm{c}$.

2 Венедиктова Т.Д. Литература как опыт. «Буржуазный читатель» как культурный герой. М.: Новое литературное обозрение, 2018. 280 с.

3 Диккенс Ч. Собр. соч.: в зо т. / под ред. А.А. Аникста и В.В. Ивашевой. М.: Гослитиздат, 1957-1963.

4 Урнов М. Предметность в стиле (Диккенс) // Типология стилевого развития Нового времени: Классический стиль: Соотношение гармонии и дисгармонии в стиле. М.: Наука, 1976. С. 473-493.

5 Arnold M. Poems. London: Longman. Brown, Green, and Longmans, I853. xxxvi, $248 \mathrm{p}$.

6 Cohen T. Metaphor and the Cultivation of Intimacy // Critical Inquiry. $\mathbf{9 7 8 .}$ Vol. 5, no I. P. 3-I2.

7 Cooper D.E. Metaphor. Aristotelian Society Series. Oxford: Basil Blackwell, I986. $282 \mathrm{p}$.

го Волошинов В.Н. Слово в жизни и слово в поэзии // Звезда. І926. № 6. С. 253. 
Dames $N$. Theories of the novel // The Cambridge History of Literary Criticism. Cambridge: Cambridge University Press, 2013. Vol. VI: The Nineteenth Century, I830-I9I4. Ed. by M.A.R. Habib. P. 506-523.

9 Dickens C. Dealings with the Firm of Dombey and Son, Wholesale, Retail, and for Exportation. London: Bradbury and Evans, I848. xvi, 624 p.

IO Dickens C. Hard Times. For These Times. London: Bradbury \& Evans, I854. viii, 352 p.

II Eliot $S$. The Business of Victorian publishing // The Cambridge Companion to the Victorian Novel. Second edition. Ed. by D. David. New York: Cambridge University Press, 20I2. P. 36-6I.

I2 Flint $K$. The Victorian Novel and Its Readers // The Cambridge Companion to the Victorian Novel. Second edition. Ed. by D. David. New York: Cambridge University Press, 2012. P. I3-35.

I3 Forster J. The Life of Charles Dickens. I872-74. 2 vols. Everyman Library edition. London: Dent, 1966.

I4 Harris W.V. Bakhtinian Double Voicing in Dickens and Eliot // ELH. I990. Vol. 57, no 2. P. $445^{-458 .}$

I5 Lewes G.H. Principles of Success in Literature. Boston: Allyn and Bacon and Chicago, I89I. I63 p.

I6 Menke R. Telegraphic Realism. Victorian Fiction and Other Information Systems. Stanford (CA): Stanford University Press, 2008. viii, 32I p.

I7 Slater M. Charles Dickens. New Haven and London: Yale University Press, 2009. 696 p. 


\section{References}

Bakhtin M.M. Slovo v romane [Discourse in the novel]. In: Voprosy literatury i estetiki [Questions of literature and aesthetics]. Moscow, Khudozhestvennaia literatura Publ., I975. 502 p. (In Russ.)

2 Venediktova T.D. Literatura kak opyt. "Burzhuaznyi chitatel”" kak kul'turnyi geroi [Literature as experience. The bourgeois reader as a cultural hero]. Moscow, Novoe literaturnoe obozrenie Publ., 2018. 280 p. (In Russ.)

3 Dikkens Ch. Sobranie sochinenii: $v$ ot. [Collected works: in 30 vols.], ed. by A.A. Anikst and V.V. Ivasheva. Moscow, Goslitizdat Publ., I957-I963. (In Russ.)

$4 \quad$ Urnov M. Predmetnost' v stile (Dikkens) [Objectness in style (Dickens)]. In: Tipologiia stilevogo razvitiia Novogo vremeni: Klassicheskii stil': Sootnoshenie garmonii $i$ disgarmonii $v$ stile [Typology of the style development in modernity: Classic style. The balance of harmony and disharmony]. Moscow, Nauka Publ., I976, pp. 473-493. (In Russ.) Arnold M. Poems. London, Longman. Brown, Green, and Longmans, I853. xxxvi, 248 p. (In English)

6 Cohen T. Metaphor and the Cultivation of Intimacy. Critical Inquiry, I978, vol. 5, no I, pp. 3-I2. (In English) Cooper D.E. Metaphor. Aristotelian Society Series. Oxford, Basil Blackwell, I986. 282 p. (In English) Dames N. Theories of the novel. The Cambridge History of Literary Criticism. Cambridge, Cambridge University Press, 20I3. Vol. VI: The Nineteenth Century, I830-I9I4. Ed. by M.A.R. Habib, pp. 506-523. (In English)

9 Dickens C. Dealings with the Firm of Dombey and Son, Wholesale, Retail, and for Exportation. London, Bradbury and Evans, I848. xvi, 624 p. (In English) Dickens C. Hard Times. For These Times. London, Bradbury \& Evans, I854. viii, 352 p. (In English)

Eliot S. The Business of Victorian publishing. The Cambridge Companion to the Victorian Novel. Second edition. Ed. by D. David. New York, Cambridge University Press, 20I2, pp. 36-6I. (In English) Flint K. The Victorian Novel and Its Readers. The Cambridge Companion to the Victorian Novel. Second edition. Ed. by D. David. New York, Cambridge University Press, 20I2, pp. 13-35. (In English)

I3 Forster J. The Life of Charles Dickens. I872-74. 2 vols. Everyman Library edition. London, Dent, I966. (In English)

I4 Harris W.V. Bakhtinian Double Voicing in Dickens and Eliot. ELH, I990. Vol. 57, no 2, pp. 445-458. (In English)

Lewes G.H. Principles of Success in Literature. Boston, Allyn and Bacon and Chicago, I891. I63 p. (In English) 
I6 Menke R. Telegraphic Realism. Victorian Fiction and Other Information Systems. Stanford (CA), Stanford University Press, 2008. viii, 32I p. (In English)

I7 Slater M. Charles Dickens. New Haven and London, Yale University Press, 2009. 696 p. (In English) 